\title{
Prevalens dan Faktor Prediktor dari Kemampuan Berjalan Pasien Palsi Serebral pada Masa Anak di Rumah Sakit Gipto Mangunkusumo dan Yayasan Pembinaan Anak Cacat
}

\author{
Primo Parmato, Luh Karunia Wahyuni, Aryono Hendarto \\ Departemen Ilmu Kesehatan Fakultas Kedokteran Universitas Indonesia Anak/Rumah Sakit Cipto \\ Mangunkusumo, Jakarta
}

\begin{abstract}
Latar belakang. Permasalahan palsi serebral (PS) yang menjadi perhatian bagi orangtua adalah kemampuan berjalan.

Tujuan. Mengetahui prevalens kemampuan berjalan pasien PS dan faktor prediktor yang berhubungan terhadap kemampuan berjalan pasien PS pada masa anak.

Metode. Dilakukan penelitian terhadap 102 pasien PS berusia 6 tahun ke atas dengan pengisian kuesioner melalui wawancara orang tua dan melihat rekam medis di RSCM dan YPAC.

Hasil. Duapuluh tujuh (26,5\%) pasien berjalan tanpa alat bantu, $13(12,7 \%)$ pasien berjalan dengan alat bantu, dan 62 (60,8\%) pasien tidak berjalan walau dengan alat bantu. Faktor prediktor yang bermakna secara statistik adalah mampu duduk tanpa topangan sebelum usia 2 tahun ( $<<0,001$; OR=6,89; IK 95\%=2,4219,71) dan tipe PS spastik unilateral (OR=7,36; IK 95\%=1,86-29,18).

Kesimpulan. Prevalens kemampuan berjalan pasien PS di RSCM dan YPAC adalah 26,5\% berjalan tanpa alat bantu, 12,7\% berjalan dengan alat bantu, dan 60,8\% tidak berjalan walaupun dengan alat bantu. Faktor prediktor yang berhubungan dengan kemampuan berjalan pada masa anak adalah mampu duduk tanpa topangan sebelum usia 2 tahun dan tipe spastik unilateral. Sari Pediatri 2014;16(1):22-8.
\end{abstract}

Kata kunci: palsi serebral, kemampuan berjalan, prevalens, faktor prediktor, masa anak

Alamat korespondensi:

Dr. Primo Parmato, SpA. Departemen Ilmu Kesehatan Anak Rumah Sakit Cipto Mangunkusumo, Jl. Diponegoro No. 71, Senen, Jakarta Pusat. Telp (021) 391 8301-11.Email: primo_p@idai.or.id

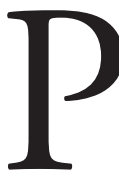

alsi serebral (PS) adalah salah satu gangguan fisis penyebab utama gangguan pertumbuhan dan perkembangan anak. Palsi serebral berpotensi menyebabkan gangguan motorik dan perkembangan seperti berbicara, belajar, dan lain-lain. Gangguan pertumbuhan dan perkembangan ditemui pada lebih kurang 17\% anak di Amerika Serikat. ${ }^{1-5}$ 
Prevalensi PS pada anak usia 3-10 tahun diperkirakan antara 2-4 kasus per 1000 anak. Dana yang dikeluarkan untuk merawat pasien PS diperkirakan mencapai US $\$ 8,2$ milyar di Amerika Serikat pada tahun 2002. ${ }^{2}$ Liu $\mathrm{dkk}^{6}$ melaporkan bahwa prevalensi PS pada anak usia kurang dari 7 tahun di Cina sebesar 1,6 kasus per 1000 anak atau diperkirakan terdapat 310.000 anak. Saat ini, di Indonesia, belum terdapat data prevalens kejadian PS. Laju insidens PS adalah 1 tiap 34.000 penduduk. Dengan demikian, jika jumlah penduduk Indonesia diperkirakan 230 juta penduduk, maka diperkirakan terdapat 7.000 penderita PS di Indonesia. ${ }^{7}$ Sejumlah 56 pasien dengan PS berobat ke poliklinik anak Rumah Sakit Cipto Mangunkusumo (RSCM) antara Januari 2010 - Januari 2011.

Permasalahan PS yang menjadi perhatian bagi orangtua adalah keterlambatan perkembangan motorik, yaitu kemampuan berjalan (walking disability). Kemampuan berjalan dinilai penting karena akan memengaruhi ketergantungan terhadap lingkungan sekitar. Hasil penelitian Surveillance of Cerebral Palsy in Europe (SCPE) menunjukkan bahwa $50 \%$ dari pasien PS mampu berjalan tanpa bantuan, $20 \%$ berjalan dengan alat bantu, dan 30\% tidak dapat berjalan. ${ }^{8}$ Sampai saat ini, belum didapatkan data prevalens kemampuan berjalan pasien PS di Indonesia.

Seorang dokter spesialis anak sebagai klinisi akan berusaha menegakkan diagnosis PS dengan cara melakukan anamnesis melalui penulusuran etiologi/ faktor risiko, faktor prediktor kemampuan berjalan dan gejala lain yang menyertai seperti epilepsi, melakukan pemeriksaan fisis berupa pemeriksaan neurologis untuk mencari kelainan neurologis, serta merencanakan pemeriksaan penunjang berupa CT-scan/MRI kepala dan tatalaksana berupa fisioterapi. Apakah data-data tersebut sudah cukup untuk menjawab pertanyaan orang tua mengenai anaknya dapat berjalan atau tidak? Oleh karena itu, penelitian ini dilakukan selain untuk mencari prevalens kemampuan berjalan pasien PS, juga untuk mencari faktor-faktor prediktor pada masa anak yang berhubungan dengan kemampuan berjalan pasien PS.

\section{Metode}

Penelitian dengan desain potong lintang dilakukan penulusuran pasien yang terdaftar di Instalasi Rekam
Medis Poliklinik Rawat Jalan Departemen Ilmu Kesehatan Pasien (IKA) RSCM, dan Yayasan Pembinaan Pasien Cacat (YPAC), antara 1 Januari 2006 hingga 31 Desember 2011.

Subyek penelitian adalah pasien PS berusia 6 tahun ke atas. Subyek diambil dengan teknik convenient sampling dan dipilih yang berlokasi di DKI Jakarta atau terjangkau oleh peneliti. Subyek akan dieksklusi apabila penyebab PS bagian dari pascanatal yang terjadi setelah usia 6 bulan (misal infeksi SSP atau trauma kepala setelah usia 6 bulan); Mendapatkan injeksi botulinum toxin; Dilakukan operasi pembedahan tulang; Terdapat hidrosefalus; Terdapat pertanyaan kuesioner penelitian yang tidak terjawab karena orang tua tidak ingat dan tidak terdapat di catatan rekam medis; Pasien bertempat tinggal di luar DKI Jakarta atau di tempat yang sulit dijangkau oleh peneliti; Tidak bersedia mengikuti penelitian dengan tidak mengisi dan menandatangani lembar persetujuan untuk mengikuti penelitian.

Untuk mendapatkan data prevalens, rumus besar sampel yang digunakan adalah survei deskriptif kategorik dan didapatkan besar sampel total minimal untuk menjawab pertanyaan prevalens adalah $90 \mathrm{pa}-$ sien. Untuk menjawab apakah ada hubungan antara faktor prediktor dengan kemampuan berjalan pasien PS, digunakan rumus besar sampel berupa rule of thumb, yaitu 5-50 dikalikan dengan jumlah variabel bebas yang akan diteliti sebanyak 14 buah sehingga rentang jumlah sampel adalah 70-700 subjek. Untuk menjawab semua pertanyaan penelitian, diputuskan jumlah sampel total yang diperlukan adalah 100 subjek.

Berjalan adalah kemampuan mobilisasi di kehidupan sehari-hari dengan cara melangkahkan kaki minimal 10 langkah.? Alat bantu berjalan adalah peralatan yang dirancang untuk membantu berjalan, dapat berupa orthosis, crutches, canes, walkers, dan rollators. ${ }^{8,9}$ Mampu berjalan tanpa alat bantu (unaided walking) adalah dapat berjalan di kehidupan sehari-hari tanpa menggunakan alat bantu berjalan, walaupun dengan gaya berjalan melangkah yang lebar (gait yang lebar). ${ }^{9-11}$ Mampu berjalan dengan alat bantu (walking with assistive device) adalah dapat berjalan di kehidupan sehari-hari dengan menggunakan alat bantu berjalan. ${ }^{9-11}$ Tidak mampu berjalan walaupun dengan alat bantu (unable to walk) adalah tidak mampu berjalan di kehidupan sehari-hari walaupun menggunakan alat bantu berjalan, atau hanya dapat 
mobilisasi di kehidupan sehari-hari dengan kursi roda atau scooter. . $^{911}$

Asfiksia perinatal didefinisikan sebagai tidak langsung menangis spontan atau tampak biru saat dilahirkan. 'Kelahiran prematur adalah bayi lahir dengan usia gestasi <37 minggu. ${ }^{12}$ Bayi berat lahir rendah (BBLR) adalah bayi dengan berat lahir $<2500$ gram. Usia pasien pertama kali didiagnosis PS adalah usia pasien didiagnosis PS pertama kali di Poliklinik Rawat Jalan Departemen Ilmu Kesehatan Anak (IKA) RSCM atau di YPAC (didiagnosis saat usia $<1$ tahun atau $\geq 1$ tahun). Mikrosefal adalah ukuran lingkar kepala terletak pada skala kurang dari -2 simpangan baku kurva Nellhaus. Gangguan penglihatan, retardasi mental, dan keterlambatan bicara dikatakan "ya" jika terdapat di rekam medis atau menurut orang tua, dokter pernah menjelaskan bahwa pasien terdapat kelainan tersebut. Epilepsi dikatakan "ya”, jika kejang epilepsi masih terjadi dalam satu tahun terakhir atau tidak ada kejang, tetapi mengonsumsi obat anti epilepsi. Kelainan pencitraan kepala adalah kelainan gambaran otak pada pemeriksaan CT scan atau MRI kepala.

Tipe kelainan PS berdasarkan kelainan motorik terbagi menjadi tipe spastik unilateral (spastisitas pada sisi yang sama), tipe spastik bilateral (spastisitas di kedua sisi tubuh), dan tipe non-spastik. ${ }^{1-4,13-16}$ Keterlambatan perkembangan motorik kasar yang ditanyakan adalah mampu menahan posisi duduk tanpa topangan sebelum usia 2 tahun, mampu duduk sendiri sebelum usia 2 tahun, dan mampu berdiri sendiri sebelum usia 2 tahun. Fisioterapi dikatakan "ya", jika menurut orang tua atau rekam medis, pasien mengikuti fisioterapi secara rutin hingga pasien minimal berusia 6 tahun. Rutin didefinisikan sebagai frekuensi fisioterapi minimal $1 \mathrm{x} /$ minggu atau sesuai menurut petunjuk fisioterapis.

\section{Hasil}

Terdapat 102 subjek penelitian dengan 75 didapatkan dari 95 murid sekolah YPAC, dan 27 dari 156 pasien PS yang terdaftar di Poliklinik Rawat Jalan Departemen IKA RSCM. Rentang umur adalah 6 sampai 54 tahun dengan rerata 18,79 tahun (Tabel 1). Semua subjek memiliki catatan rekam medis yang lengkap. Prevalensi kemampuan berjalan pasien PS tertera pada Tabel 2.
Tabel 1. Sebaran karakteristik demografis subjek penelitian

\begin{tabular}{|c|c|c|}
\hline Variabel & Jumlah & Persentase \\
\hline \multicolumn{3}{|l|}{ Jenis kelamin } \\
\hline Laki-laki & 52 & 51,0 \\
\hline Perempuan & 50 & 49,0 \\
\hline \multicolumn{3}{|c|}{ Usia pertama diagnosis $<1$ tahun } \\
\hline Ya $(<1$ tahun $)$ & 74 & 72,5 \\
\hline Tidak (>1 tahun) & 28 & 27,5 \\
\hline \multicolumn{3}{|l|}{ Prematur } \\
\hline Ya & 39 & 38,2 \\
\hline Tidak & 63 & 61,8 \\
\hline \multicolumn{3}{|l|}{$\operatorname{BBLR}(<2500$ gr $)$} \\
\hline Ya $(<2500$ gr $)$ & 39 & 38,2 \\
\hline Tidak (>2500 gr) & 63 & 61,8 \\
\hline \multicolumn{3}{|l|}{ Asfiksia perinatal } \\
\hline Ya & 54 & 52,9 \\
\hline Tidak & 48 & 47,1 \\
\hline \multicolumn{3}{|l|}{ Tipe palsi serebral } \\
\hline Spastik bilateral & 77 & 75,5 \\
\hline Non spastik & 12 & 11,8 \\
\hline Spastik unilateral & 13 & 12,7 \\
\hline \multirow{2}{*}{\multicolumn{3}{|c|}{$\begin{array}{l}\text { Tidak mampu menahan posisi } \\
\text { duduk tanpa topangan hingga } \\
\text { usia } 2 \text { thn }\end{array}$}} \\
\hline & & \\
\hline Ya & 79 & 77,5 \\
\hline Tidak & 23 & 22,5 \\
\hline \multicolumn{3}{|c|}{ Tidak mampu duduk sendiri } \\
\hline \multirow{2}{*}{\multicolumn{3}{|c|}{$\begin{array}{l}\text { tanpa bantuan dari posisi } \\
\text { berbaring hingga usia } 2 \text { tahun }\end{array}$}} \\
\hline & & \\
\hline Ya & 80 & 78,4 \\
\hline Tidak & 22 & 21,6 \\
\hline Tidak mampu berdir & & \\
\hline dari posisi duduk tan & & \\
\hline & & \\
\hline $\mathrm{Ya}$ & 96 & 94,1 \\
\hline Tidak & 6 & 5,9 \\
\hline \multicolumn{3}{|l|}{ Gangguan penglihatan } \\
\hline $\mathrm{Ya}$ & 49 & 48,0 \\
\hline Tidak & 53 & 52,0 \\
\hline \multicolumn{3}{|l|}{ Terlambat bicara } \\
\hline $\mathrm{Ya}$ & 93 & 91,2 \\
\hline Tidak & 9 & 8,8 \\
\hline \multicolumn{3}{|l|}{ Epilepsi } \\
\hline $\mathrm{Ya}$ & 25 & 24,5 \\
\hline \multirow{2}{*}{\multicolumn{3}{|c|}{ Retardasi mental }} \\
\hline & & \\
\hline Ya & 79 & 77,5 \\
\hline Tidak & 23 & 22,5 \\
\hline \multicolumn{3}{|c|}{ Kelainan pencitraan kepala } \\
\hline Ya & 83 & 81,4 \\
\hline Tidak & 15 & 14,7 \\
\hline Tidak dilakukan & 4 & 3,9 \\
\hline \multicolumn{3}{|l|}{ Fisioterapi } \\
\hline Ya & 73 & 71,6 \\
\hline \multirow{2}{*}{\multicolumn{3}{|c|}{ Mikrosefal }} \\
\hline & & \\
\hline $\mathrm{Ya}$ & 45 & 44,1 \\
\hline Tidak & 57 & 55,9 \\
\hline
\end{tabular}


Primo Parmato dkk: Prevalens dan faktor prediktor dari kemampuan berjalan pasien palsi serebral

Tabel 2. Sebaran prevalens kemampuan berjalan

\begin{tabular}{lcc}
\hline Kemampuan berjalan & Jumlah & Persentase \\
\hline Berjalan tanpa alat bantu & 27 & 26,5 \\
Berjalan dengan alat bantu & 13 & 12,7 \\
Tidak dapat berjalan walau dengan alat bantu & 62 & 60,8 \\
\hline
\end{tabular}

Variabel independen atau faktor prediktor kemampuan berjalan pada pasien PS yang mempunyai nilai $\mathrm{p}<0,05$ adalah kemampuan menahan posisi duduk tanpa topangan sebelum usia 2 tahun, kemampuan duduk sendiri dari posisi berbaring sebelum usia 2 tahun, kelainan pencitraan kepala, dan tipe PS spastik unilateral (Tabel 3). Variabel kelainan pencitraan kepala didapatkan 4 subjek yang tidak dilakukan pemeriksaan pencitraan kepala. Keempat subjek ini tetap dimasukkan dalam analisis mutivariat dengan asumsi hasil pemeriksaan pencitraan kepala dengan kondisi klinis dari subjek. Tiga subjek diasumsikan mempunyai hasil pencitraan kepala yang abnormal karena terdapat mikrosefal atau tipe PS spastik bilateral, sedangkan satu subjek diasumsikan mempunyai hasil pemeriksaan yang normal karena tidak ada mikrosefal dan tipe PS non-spastik.

Hasil matrikulasi menunjukkan terdapat hubungan yang saling memengaruhi antara variabel kemampuan menahan posisi duduk tanpa topangan sebelum usia 2 tahun dengan variabel kemampuan duduk sendiri dari posisi berbaring sebelum usia 2 tahun. Dengan demikian, diputuskan untuk memilih salah satu yang dimasukkan dalam analisis mutivariat yaitu variabel kemampuan menahan posisi duduk tanpa topangan sebelum usia 2 tahun dengan pertimbangan variabel ini lebih banyak ditemukan di penelitian sebelumnya. Variabel independen yang masuk ke dalam analisis regresi logistik adalah kemampuan menahan posisi duduk tanpa topangan sebelum usia 2 tahun, kelainan pencitraan kepala, dan tipe PS. Hasil analisis regresi logistik tertera pada Tabel 4.

Berdasarkan hasil langkah kedua, maka dapat dibuat suatu formula:

$$
\begin{gathered}
\mathrm{Y}=-2,009+1,904 *(\text { Duduk tanpa topangan }<\text { usia } \\
2 \text { tahun })+1,332 *(\text { Tipe spastik unilateral })
\end{gathered}
$$

Dengan catatan: duduk tanpa topangan $\geq$ usia 2 tahun nilainya 0 , sedangkan < usia 2 tahun nilainya 1 ; Tipe PS bilateral dan non-spastik nilainya 0 , sedangkan tipe PS unilateral nilainya 1 . Rumus probabilitas mampu berjalan tanpa/dengan alat bantu adalah:

$$
\mathrm{P}=1 /(1+\exp (-\mathrm{y}))
$$

Probabilitas mampu berjalan tanpa/dengan alat bantu dihubungkan dengan tipe PS dan kemampuan menahan duduk tanpa topangan tertera pada Tabel 5 .

\section{Pembahasan}

Penelitian ini merupakan penelitian potonglintang dengan menggunakan data primer dari hasil wawancara dengan orang tua subjek dan data sekunder dari rekam medis tempat subjek berobat. Data primer hasil wawancara merupakan data yang didapat melalui memori sehingga masih mungkin terdapat recall bias, terutama apabila data tidak ditemukan di rekam medis. Rentang umur yang lebar antara usia 6-54 tahun dapat menyebabkan bias mengenai prognosis kemampuan berjalan. Hal tersebut dikarenakan terdapat rentang yang lebar mengenai lama intervensi yang dilakukan, dan kapan mulai dilakukannya intervensi tersebut.

Prevalens kemampuan berjalan pada survey Eropa yang dilakukan oleh Beckung dkk ${ }^{9}$ menyatakan bahwa pasien PS yang tidak dapat berjalan baik dengan atau tanpa alat bantu sejumlah 30\%, yang berjalan dengan alat bantu 16\%, yang berjalan tanpa alat bantu 54\%. Pada penelitian ini, prevalens pasien PS yang tidak dapat berjalan baik dengan atau tanpa alat bantu adalah $60,8 \%$, yang dapat berjalan dengan alat bantu $12,7 \%$, yang dapat berjalan tanpa alat bantu $26,5 \%$. Perbedaan hasil tersebut masih mungkin disebabkan karena data hasil penelitian ini hanya diambil dari dua tempat, yaitu YPAC dan Poliklinik Rawat Jalan Departemen IKA-RSCM. Selain itu, pemilihan subjek dilakukan secara convenient sampling yaitu hanya mengambil subjek penelitian yang bisa dihubungi melalui telepon dan tempat tinggal yang terjangkau oleh peneliti. Kedua hal tersebut menyebabkan hasil data prevalensi 
Tabel 3. Sebaran faktor prediktor berdasarkan kemampuan berjalan

\begin{tabular}{|c|c|c|c|c|}
\hline Karakteristik demografis & $\begin{array}{c}\text { Berjalan tanpa/ } \\
\text { dengan alat bantu }\end{array}$ & $\begin{array}{l}\text { Tidak berjalan walau } \\
\text { dengan alat bantu }\end{array}$ & $\mathrm{p}$ & RO (IK 95\%) \\
\hline \multicolumn{5}{|l|}{ Jenis kelamin (\%) } \\
\hline Laki-laki & $31(59,6)$ & $21(40,4)$ & 0,805 & \multirow{2}{*}{$0,91(0,41-2,01)$} \\
\hline Perempuan & $31(62,0)$ & $19(38,0)$ & Reff & \\
\hline \multicolumn{5}{|l|}{ Asfiksia perinatal (\%) } \\
\hline Tidak & $19(39,6)$ & $29(60,4)$ & 0,943 & \multirow{2}{*}{$1,03(0,46-2,28)$} \\
\hline $\mathrm{Ya}$ & $21(38,9)$ & $33(61,1)$ & Reff & \\
\hline \multicolumn{5}{|c|}{$\begin{array}{l}\text { Usia pertama kali didiagnosis PS } \\
(\%)\end{array}$} \\
\hline$<1$ tahun & $28(37,8)$ & $46(62,2)$ & 0,643 & \multirow[t]{2}{*}{$1,23(0,51-2,98)$} \\
\hline$\geq 1$ tahun & $12(42,9)$ & $16(57,1)$ & Reff & \\
\hline \multicolumn{5}{|l|}{ Keterlambatan bicara (\%) } \\
\hline Tidak & $3(33,3 \%)$ & $6(66,7)$ & 1,000 & \multirow[t]{2}{*}{$0,76(0,18-3,22)$} \\
\hline $\mathrm{Ya}$ & $37(39,8 \%)$ & $56(60,2)$ & Reff & \\
\hline \multicolumn{5}{|l|}{ Epilepsi (\%) } \\
\hline Tidak & $29(37,7)$ & $48(62,3)$ & 0,573 & \multirow[t]{2}{*}{$0,77(0,31-1,92)$} \\
\hline $\mathrm{Ya}$ & $11(44,0)$ & $14(56,0)$ & Reff & \\
\hline \multicolumn{5}{|l|}{ Gangguan penglihatan (\%) } \\
\hline Tidak & $25(47,2)$ & $28(52,8)$ & 0,087 & \multirow[t]{2}{*}{$2,02(0,89-4,56)$} \\
\hline $\mathrm{Ya}$ & $15(30,6)$ & $34(69,4)$ & Reff & \\
\hline \multicolumn{5}{|l|}{ Retardasi mental (\%) } \\
\hline Tidak & $11(47,8)$ & $12(52,2)$ & 0,337 & \multirow[t]{2}{*}{$1,58(0,62-4,04)$} \\
\hline Ya & $29(36,7)$ & $50(63,3)$ & Reff & \\
\hline \multicolumn{5}{|l|}{ Prematur (\%) } \\
\hline Tidak & $29(46,0)$ & $34(54,0)$ & 0,073 & \multirow[t]{2}{*}{$2,17(0,92-5,11)$} \\
\hline $\mathrm{Ya}$ & $11(28,2)$ & $28(71,8)$ & Reff & \\
\hline \multicolumn{5}{|l|}{ BBLR (\%) } \\
\hline Tidak & $29(46,0)$ & $34(54,0)$ & 0,073 & \multirow[t]{2}{*}{$2,17(0,92-5,11)$} \\
\hline Ya & $11(28,2)$ & $28(71,8)$ & Reff & \\
\hline \multicolumn{5}{|l|}{ Mikrosefal (\%) } \\
\hline Tidak & $19(33,3)$ & $38(66,7)$ & 0,171 & \multirow[t]{2}{*}{$0,57(0,26-1,28)$} \\
\hline Ya & $21(46,7)$ & $24(53,3)$ & Reff & \\
\hline \multicolumn{5}{|c|}{ Duduk tanpa topangan (\%) } \\
\hline$<$ usia 2 tahun & $17(73,9)$ & $6(26,1)$ & $<0,001$ & \multirow[t]{2}{*}{$6,89(2,42-19,71)$} \\
\hline$\geq$ usia 2 tahun & $23(29,1)$ & $56(70,9)$ & Reff & \\
\hline Dapat duduk sendiri (\%) & & & & \\
\hline$<$ usia 2 tahun & $16(72,7)$ & $6(27,3)$ & $<0,001$ & $6,22(2,17-17,84)$ \\
\hline zusia 2 tahun & $24(30,0)$ & $56(70,0)$ & Reff & \\
\hline Dapat berdiri sendiri (\%) & & & & \\
\hline$<$ usia 2 tahun & $4(66,7)$ & $2(33,3)$ & 0,207 & $3,33(0,58-19,12)$ \\
\hline$\geq$ usia 2 tahun & $26(37,5)$ & $60(62,5)$ & Reff & \\
\hline Tipe PS (\%) & & & & \\
\hline Spastik unilateral & $10(76,9)$ & $3(23,1)$ & 0,004 & $7,36(1,86-29,18)$ \\
\hline Non spastik & $6(50,0)$ & $6(50,0)$ & 0,226 & $3,33(0,60-18,54)$ \\
\hline Spastik bilateral & $24(31,2)$ & $53(68,8)$ & Reff & \\
\hline Kelainan pencitraan kepa & & & & \\
\hline Tidak & $11(68,8)$ & $5(31,3)$ & 0,008 & $4,32(1,37-13,63)$ \\
\hline Ya & $29(33,7)$ & $57(66,3)$ & Reff & \\
\hline Fisioterapi (\%) & & & & \\
\hline $\mathrm{Ya}$ & $29(39,7)$ & $44(60,3)$ & 0,867 & $0,93(0,38-2,25)$ \\
\hline Tidak & $11(37,9)$ & $18(62,1)$ & Reff & \\
\hline
\end{tabular}


Tabel 4. Analisis regresi logistik

\begin{tabular}{lcccc}
\hline Variabel & Koefisien & SE & $p$ & OR (95\% IK) \\
\hline Langkah 1 & & & & \\
$\quad$ Duduk tanpa topangan < usia 2 tahun & 1,854 & 0,560 & 0,001 & $6,38(2,13-19,14)$ \\
$\quad$ Citra kepala normal & 0,811 & 0,597 & 0,174 & $2,25(0,69-7,26)$ \\
$\quad$ Tipe PS unilateral & 1,196 & 0,533 & 0,025 & $3,31(1,16-9,39)$ \\
Konstanta & $-2,528$ & 0,776 & 0,001 & 0,08 \\
Langkah 2 & & & & \\
$\quad$ Duduk tanpa topangan < usia 2 tahun & 1,904 & 0,554 & 0,001 & $6,71(2,27-19,89)$ \\
$\quad$ Tipe PS unilateral & 1,332 & 0,519 & 0,010 & $3,79(1,37-10,47)$ \\
$\quad$ Konstanta & $-2,009$ & 0,641 & 0,002 & 0,13 \\
\hline
\end{tabular}

Hosmer \& Lemeshow Test $=0,415 ;$ Nagelkerke $r^{2}=0,260 ; A U C=0,734(0,629-0,838)$

Tabel 5. Probabilitas mampu berjalan tanpa/dengan alat bantu

\begin{tabular}{lcc}
\hline Kemampuan menahan posisi duduk & \multicolumn{2}{c}{ Tipe PS } \\
\cline { 2 - 3 } tanpa topangan $<$ usia 2 tahun & Spastik unilateral & Spastik bilateral/non spastik \\
\hline Mampu & 0,7733 & 0,4737 \\
Tidak mampu & 0,5963 & 0,1183 \\
\hline
\end{tabular}

masih belum dapat digeneralisasikan sebagai data dari populasi pasien PS.

Penyebab kedua adalah terdapatnya perbedaan prevalens tipe PS spastik bilateral dan tipe PS spastik unilateral. Pada survey Beeckung dkk, ${ }^{9}$ tipe spastik bilateral mencakup 54\% dan tipe spastik unilateral $32 \%$. Pada penelitian ini, tipe spastik bilateral ditemukan $75,5 \%$ dan tipe spastik unilateral $11,8 \%$. Perbedaan prevalens tipe PS ini kemungkinan disebabkan oleh perbedaan prevalens penyebab/faktor risiko dari PS. Pada survey Beckung $\mathrm{dkk},{ }^{9}$ prematuritas sebagai faktor risiko PS mencakup 44,1\%, sedangkan pada penelitian ini $38,2 \%$.

Studi Wu dkk ${ }^{17}$ menyatakan bahwa tahapan usia perkembangan motorik kasar sebagai faktor prognostik kemampuan berjalan yang terpenting, dengan variabel kemampuan menahan posisi duduk sebelum usia 2 tahun. Studi Sala $\mathrm{dkk}^{18}$ juga menyatakan bahwa kemampuan menahan posisi duduk sebelum usia 2 tahun juga merupakan faktor prediktor kemampuan berjalan pada pasien PS. Pada penelitian ini, variabel menahan posisi duduk tanpa topangan sebelum usia 2 tahun merupakan faktor prediktor terpenting terhadap kemampuan berjalan pada pasien PS. Berdasarkan usia 2 tahun ini, maka diharapkan adanya intervensi dini yang dilakukan sebelum anak mencapai usia 2 tahun seperti fisioterapi sedini mungkin.

Studi yang dilakukan oleh Beckung dkk ${ }^{9}$ menyatakan bahwa tipe PS berhubungan dengan kemampuan berjalan pada pasien PS, dengan tipe spastik unilateral adalah tipe PS dengan proporsi terbesar yaitu dapat berjalan (97\%). ${ }^{9}$ Pada penelitian ini, tipe PS yang paling beprediktor terhadap kemampuan berjalan adalah tipe spastik unilateral dengan proporsi yang dapat berjalan.

Variabel fisioterapi tidak berhubungan dengan kemampuan berjalan disebabkan sulit menentukan kriteria yang menyatakan bahwa fisioterapi telah berhasil dan efektif. Hal yang utama menentukan keberhasilan fisioterapi adalah keterlibatan orangtua menerapkan fisioterapi di rumah. ${ }^{19}$ Sebuah program intervensi berbasis keluarga yang dikenal dengan COPCA (coping and caring for infants with neurological dysfunction) diperkenalkan pada tahun 2007. Program ini menekankan pelatihan fungsi tubuh melalui penerapan dalam kegiatan sehari-hari oleh keluarga. ${ }^{20}$ Data yang diperoleh penelitian ini hanyalah frekuensi fisioterapi saat kunjungan ke rumah sakit sehingga kurang adekuat dalam menentukan efektivitas fisioterapi. 


\section{Kesimpulan}

Prevalens kemampuan berjalan pasien PS di RSCM dan YPAC yang dapat berjalan tanpa alat bantu adalah $26,5 \%$, berjalan dengan alat bantu $12,7 \%$, dan tidak dapat berjalan walaupun dengan alat bantu 60,8\%. Faktor prediktor pasien PS pada masa anak di RSCM dan YPAC yang berperan terhadap kemampuan berjalan baik dengan atau tanpa alat bantu adalah kemampuan menahan posisi duduk sebelum usia 2 tahun dan adanya tipe spastik unilateral, dengan faktor prediktor yang paling berperan adalah kemampuan menahan posisi duduk sebelum usia 2 tahun.

\section{Daftar pustaka}

1. Jones MW, Morgan E, Shelton JE, Thorogood C. Cerebral palsy: introduction an diagnosis (part 1). J Pediatr Health Care 2007;21:146-52.

2. Koman LA, Smith BP, Shilt JS. Cerebral palsy. Lancet 2004;363:1619-31.

3. Krigger KW. Cerebral palsy: an overview. Am Fam Physician 2006;73:91-100.

4. Lin JP. The cerebral palsies: a physiological approach. J Neurol Neurosurg Psychiatry 2003;74:23-9

5. Taft LT. Cerebral palsy. Pediatr Rev 1995;16:411-8.

6. Liu JM, Li S, Lin Q, Li Z. Prevalence of cerebral palsy in china. Int J Epid 1999;28:949-54.

7. Statistics by country for cerebral palsy (diakses pada tanggal 30 April 2013). Diunduh dari: http://www. rightdiagnosis.com/clcerebral_palsy/stats-country.htm.

8. Surveillance of Cerebral Palsy in Europe. Prevalence and characteristics of children with cerebral palsy in Europe. Dev Med Child Neurol 2002;44:633-40.

9. Beckung E, Hagberg G, Uldall P, Cans C. Probability of walking in children with cerebral palsy in Europe. Pediatrics 2008;121:e187-92.

10. Palisano R, Rosenbaum P, Bartlett D, Livingston M.
Gross motor function classification system expanded and revised. 2007 (diakses tanggal 8 Juli 2011). Diunduh dari: http://www.canchild.ca/Portals/O/outcomes/pdf/GMFCSER.pdf.

11. Rosenbaum PL, Walter SD, Hanna SE, Palisano RJ, Russell DJ, Raina P, dkk. Prognosis for gross motor function in cerebral palsy: creation of motor development curves. JAMA 2002;288:1357-63.

12. Wikojosastro H, Abdul Bari Saifuddin, Triatmojo Rachimhadhi. Dalam: Buku Ajar Ilmu Kebidanan. Edisi ke- 5. Jakarta: Balai Penerbit FKUI;1999.h.781-83.

13. Adyana IMO. Cerebral palsy ditinjau dari aspek neurologi. Cermin Dunia Kedokteran 1995;104:3740.

14. Passat J. Kelainan perkembangan. Dalam: Soetomenggolo TS, Ismael S, penyunting. Buku ajar neurologi pasien. Jakarta: IDAI;1999.h.104-36.

15. Sankar C, Mundkur N. Cerebral palsy-definition, classification, etiology and early diagnosis. Ind J Ped 2005;72:865-8

16. Shanks DE. An overview of cerebral palsy and evolving trends in management. 2000 (diakses pada tanggal 4 Juli 2011). Diunduh dari: http://www.dcmsonline.org/ jax-medicine/2000journals/march2000/cerebral.htm.

17. Wu YW, M.Day S, Strauss DJ, M.Shavelle R. Prognosis for ambulation in cerebral palsy: A population-based study. Pediatrics 2004;114:1264-71

18. Sala DA, Grant AD. Prognosis for ambulation in cerebral palsy. Dev Med Child Neurol 1995;37:1020-6.

19. New York State Department of Health Division of Family Health Bureau of Early Intervention. Clinical Practice Guideline, Motor Disorders, Assesment and Intervention for Young Children (age 0-3 year). New York: New York State Department of Health; 2006.

20. Carlberg EB, Hadders-Algra M. Postural control in sitting children with cerebral palsy. Dalam: Carlberg EB, Hadders-Algra M, penyunting. Postural control: A key issue in developmental disorders. London: Mac Keith Press; 2008. h.74-96. 